\section{MY FRIEND MORGAN: AN EXERCISE IN ETHICS}

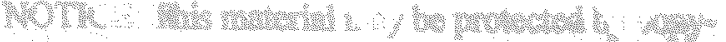

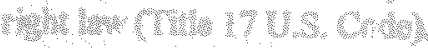

Nancy E. Landrum

Morehead State University

The discussion of ethics in management and organizational behavior classrooms is growing more common. Increased emphasis has been placed on ethics in management education within business schools, stimulated by American Association of Collegiate Schools of Business requirements. Colleges of business often have an entire course devoted to the coverage of ethics.

Although the necessity for ethical decision making cannot be disputed, instructors do not have abundant resources on which to draw. Journals and texibooks have few exercises for demonstrating ethical decision making, and it can be particularly difficult to bring the discussion to life for students with limited work experience.

The exercise presented here, My Friend Morgan, will help instructors create fun and interesting ethics discussions. This exercise uses a survey to identify students' ethical behaviors. A case scenario is then created using the composite scores from the surveys. The students do not know the case scenario comes from their own survey results, and the exercise concludes with a discussion of the case scenario. A unique feature of this teaching tool is that the survey and case scenario are flexible and can be customized to the instructor's course content. Students are unknowingly given the opportunity to cval-

Author's Note: I wish to thank John Kilpatrick, Shirley Matthiesen, and Tracy King as well as David Boje, Brad Gilbreath, and the reviewers at $J M E$ for their helpful comments on earlier versions of this article. This exercise was presented at the Organizational Behavior Teaching Conference at University of LaVerne, LaVerne, California June 1998. PJease address all correspondence to Nancy E. Landrum, Morehead State University, College of Business, Management Department, 313 Cumbs Building, UPO 778, Norehead, KY 40351; (phone) 606-783-2164; (fax) 606-783-5025; (e-mail) n landnum@morehead-stedu

JOURNAL OF MANAGEMENT EDUCATION, Vol. 25 No. 5, October $2001.606-616$ 2001 Sage Publications uate their own ethical behavior by participating in this exercise. This is another unique feature of My Friend Morgan, and it allows instructors to personalize the exercise to the participants' personal behavior. Feedback from students suggests that they particularly enjoy the personal nature of this exercise. The exercise can be used in conjunction with discussions on theories of ethical decision making. The teaching tool is simple to use and produces interesting and lively discussions.

\section{Ethics and Organizational Behavior}

Ethics is the study of what is right and wrong in decision making. Ethics involves beliefs, morals, attitudes, and actions. The discussion of ethics is particularly germane to organizational behavior and management education.

Although many management and organizational behavior teaching texts address the topic of ethics, there are relatively few classroom activities or exercises to make the discussion salient. Textbooks typically offer case scenarios and questions for discussion, but they are surprisingly similar in that they each pose an ethical dilemma and ask students to answer questions regarding the situation. Similarly, The Journal of Business Ethics offers scenarios for student discussion followed by responses of professional managers. These types of exercises remain detached from the students.

In a review of the Journal of Management Education, only three business ethics exercises have been published in recent years (Collins, 1999; Dennis \& Stroh, 1997; Mallinger, 1997). These exercises are more applied and interactive than the discussions offered in textbooks. Current events are also repletc with examples, which can lead to interesting discussions of ethics.

Whether instructors are using textbooks, journals, or current events for ethics cases and exercises, it can be difficult to make discussions of business ethics pertinent to students with limited work experience. It is also difficult to create a discussion in which each member of the class is personally involved in the scenario. The following exercise can add to the limited stock of resources available for instructors and is unique in its flexibility and its ability to be personalized.

\section{Exercise Synopsis}

The instructor will survey students' behaviors and then create a case scenario using the survey responses. The sample case provided in Appendix B was created from the results of a survey given in an MBA course but can be 
adapted to any classroom, and the scenario can be created using any type of setting relevant to the course. The sample case scenario provided takes place in the sales department of a large corporation. The case places the reader in a dilemma. A friend has asked for a recommendation for a promotion. Although the friend is regarded positively within the company, he or she has occasionally engaged in questionable personal and professional behaviors (taken from the survey responses). Because the scenario places the reader in the position of friend of Morgan, the reader is aware of these questionable behaviors and is faced with the decision of whether to recommend Morgan for promotion.

The objectives of this exercise are to:

- help students recognize opinions about ethical behavior,

- recognize the possible lax awareness of one's own ethical behavior and to become aware of and accountable for that behavior.

- encourage students to consider the implications of their behavior,

- provide an opportunity for discussing relationships between personal behavior and professional responsibility,

- provide a vehicle for discussing theories of ethical behavior.

Questions to stimulate classroom discussion are included in Appendix C.

\section{Procedures}

\section{STEP 1: EARLY IN THE}

SEMESTER-GIVING THE SURVEY

As the instructor, you can use the survey provided in Appendix A, or you can develop your own survey of questionable behaviors. By developing your own survey, you can tailor questions to those more appropriate to the content area under study. The accompanying survey was used in a master of business administration program and is geared toward management and ethics issues hut has also been used in undergraduate introductory management classes in discussions of ethics.

If developing your own survey, it is recommended that surveys be approximately 15 to 20 questions. The questions should be related to ethical behavior and should include a range of personal off-work behavior as well as workrelated behaviors. Any of the survey questions can be specific to the class content area. Surveys should be conducted in a confidential manner with anonymity guaranteed for participants. For example, I ask students to answer truthfully and not to put their names on the survey. I tell them the survey is being used to collect data for a research study. I instruct the sludents that I will pass around an envelope and they are to put their own surveys into the envelope. They will not be asked to pass the surveys to the end of the row; therefore, their anonymity and confidentiality will be preserved as no one else will see their responses. Surveys should be taken early in the semester and should be removed in time from the actual case discussion.

A note of caution: Students often checkmark that they have engaged in a particular behavior in the past year but fail to checkmark that they have engaged in the same behavior during their lifetime. You should point this out to students as they take the survey and also pay particular attention to this during tabulation.

\section{STEP 2: DEVELOPING YOUR CASE SCENARIO}

Once the survey is completed, the results should be tabulated into it frequency distribution. Choose those questions answered affirmatively by mosl participants for inclusion in the case scenario you will develop. For example, in the accompanying sample survey and case, only those survey results answered affirmatively by $32 \%$ or more of the students were used. Those survey questions that had less than $32 \%$ frequency were not included because they were outliers and most respondents would not be able to take ownership of those behaviors during the case discussion to take place later in the course. It is important that students be able to identify with the behaviors during the case discussion.

A case scenario is then developed from the survey results. The sample case scenario developed by the author in an MBA course is seen in Appendix B. In the sample case, the items taken from the survey have been italicized for purposes of illustration. In the case scenario that you will distribute to your students, the items would not be italicized.

As you develop your case scenario, it is important to distinguish between those behaviors that occurred during Morgan's lifetime (possibly a sign of misguided youth) and those behaviors that have occurred in the past year (possibly more representative of Morgan's current behavior). In addition, every effort should be made to create a positive image of Morgan at the current company so that Morgan is suitable for promotion if one was unaware of Morgan's personal behaviors. In developing your case scenario, you should make Morgan's character well balanced and try to avoid weighting Morgan's character in either a negative or positive direction. In addition, I have sclected the name Morgan to be ambiguous, and I have avoided reference to gender. Be creative and have fun developing your case. 


\section{STEP 3. LATER IN THE SEMESTER-}

\section{DISTRIBUTING THE CASE SCENARIO}

After a suitable period of time has elapsed from taking the survey, distribute the My Friend Morgan case scenario that you created. I usually schedule this step near midterm, or approximately 6 weeks after the survey was given Initially, it is important that participants do not know that this case was developed from their earlier survey results or that Morgan is a composite character based on their behaviors. The case scenario should be distributed and discussed.

\section{STEP 4: THE CLASS DISCUSSION}

Sample discussion questions that were used with the accompanying sample case are included in Appendix C. The questions often generate interesting discussion. To enhance discussion, the instructor can ask groups of students to argue the pros and cons of each question. The instructor can also develop his or her own questions unique to his or her own survey and case scenario.

After discussing the questions, the instructor should refer back to the survey taken earlier in the semester but not yet disclose that Morgan's character was developed from the survey results. Show and discuss the results of the survey. Survey results can be displayed to the class on an overhead projector. I generally show the original survey and write in the raw score of positive responses to each question. Students are usually curious how others responded in comparison to themselves. In addition, I show a bar graph of those responses included in the survey that shows the comparison of current behavior versus lifetime bchavior.

\section{STEP 5: DEBRIEHING}

Point out the similarities between your students' responses and Morgan's behavior. At this time you should tell participants that Morgan was created from their survey results and is in fact a reflection of their own ethical behavior. Students often find this fact interesting and are willing to engage in further discussion. I ask if they are surprised at the survey results or if they want to discuss any of the survey resulis in depth. Students may disclose their answers on items they view as less deviant but rarely disclose their answers on those items they view as more deviant. Similarly, students may disclose behaviors that occurred in their lifelime but may be less willing to disclose bchaviors that occurred within the past year.

Now that the case scenario is more personalized, you may want to reintroduce some of the discussion questions and see if responses vary from prior responses. In my experience, students still support their original decision and will not change their responses.

In using the accompanying survey and case scenario in an MBA class, I observed a sharp demarcation between foreign and American students. In discussions of the case scenario, foreign students were more accepting of Morgan's behaviors, whereas American students were more critical of Morgan's behaviors. There may also be cultural or religious differences that could affect responses. It is interesting to point out to students their own ethical behavior (from the survey) and that often there can he inconsistencies between our self-concept and our actual behavior. This provides a lead-in to a discussion of Argyris and Schon's (1974) theory, which is elaborated in the following discussion.

During the case discussion and debriefing, the instructor should ask students to explain why they would or would not recommend Morgan (Discussion Question 8 in Appendix C). This discussion can then transition into theories of ethical reasoning and decision making. A brjef review of theories that could be incorporated into the discussion follows.

\section{Teaching About Ethics}

In a review of introductory management textbooks by Daft (1991), Daft and Marcic (1998), Robbins and Coulter (1999), and Jones, George, and Hill (1998), it was found that each text has a chapter dealing with ethics and that they primarily cover the model put forth by Cavanaugh, Moberg, and Velasquez (1981). Cavanaugh et al. presented the following threc models of ethical decision making: utilitarian, moral rights, and justice. The utilitarian model is concerned with outcomes or consequences and what is the greatest good. The moral rights model is concerned with protecting the rights of individuals. The justice model is concerned with equitable and fair distribution.

In addition, Daft (1991) and Daft and Marcic (1998) drew on Tulega (1987), Kekes (1988), Wiley (1995), and Longnecker. McKinney, and Moore (1988). Both Daft and Daft and Marcic discussed individualism, which states that decisions that promote the individual's best interest will also in the long run promote society's best interest. Robbins and Coulter (1999) introduced Donaldson and Dunfee's (1994) integrative social contracts theory that sug gests we make ethical decisions by comparing reality with the ideal. The preceding models are appropriate to undergraduate discussions of ethics.

For a more philosophical discussion appropriate to graduate-lcvel classes Donaldson and Werhane (1996) covered the following three theories of ethical reasoning: (a) consequentialism (ethical egoism and utilitarianism), 
(b) deontological (Kantian and contractarian), and (c) human nature. Consequentialism focuses on the consequences of the action and whether a particular behavior will lead to a desired outcome. Consequentialism is further divided into ethical egoism and utilitarianism. In ethical egoism, one seeks to do what is best for oneself. In utilitarianism, one seeks to do what is best for the overall good. Deontological decisions focus on following rules of behavior. Deonotological decisions are of two types, Kantian and contractarian. Kantian deontology believes in an individual's duty to behave appropriately regardless of the behavior or the consequences. Contractarian deontology believes in social principles that should govern all people's behavior. Human nature ethics supports the notion that all individuals are inherently good, we strive for self-actualization, and behavior should be consistent with this goal.

Yet another approach for discussing ethical decision making and that is appropriate and interesting at any academic level is to follow Argyris and Schon's (1974) espoused theory versus theory in use. A person's verbal account of how they would behave under a set of given circumstances is termed as his or her espoused theory. Espoused theory is what is generated from most ethics case discussions provided in textbooks. However, a person's actual observed behavior is termed as his or her theory in use. Argyris and Schon pointed out that a person's espoused theory and theory in use may be contradictory and that a persun may not even be aware of the inconsistency. Using this framework to discuss the case may help students become more mindful of disconnects between their espoused theory and theory in use.

\section{Summary}

Ethics is an important and necessary topic in management education. Although current events lend themselves to numerous discussions of ethical behavior, our teaching materials have few exercises available for the classroom. My Friend Morgan offers instructors another tool for bringing ethics discussions to life in the classroom. The exercise can be used as an applied example of ethical decision-making models.

My Friend Morgan can be used at any course level, is flexible, and can be adapted to any course topic.

\section{Appendix A}

\section{My Friend Morgan}

\section{Survey}

Please use a checkmark to indicate a yes or true answer. Please leave the line blank to signify a no or false answer.

$\begin{aligned} & \text { During your } \\ & \text { lifetime, have } \\ & \text { you ever: }\end{aligned}$
$\begin{aligned} & \text { In the } \\ & \text { past year, } \\ & \text { have you: }\end{aligned}$
stolen something from work, a friend, a family
member, etc.?
shoplifted?
lied or not told the truth?
cheated on your spouse or significant other?
kept merchandise or money when the sales clerk or
company made a mistake in your favor?
lied on an employment application?




\section{Appendix B \\ Case Scenario}

You have just hung up from speaking with your friend Morgan and your supervisor is due in your office any time now.

You have known Morgan for many years. You attended the same high school and knew Morgan as an acquaintance but wouldn't say the two or you were friends Whereas you enjoyed academic and athletic pursuits, Morgan was rebellious and often in trouble. During high school, it was a known fact that Morgan had been caugh shoplifting but didn't suffer any real consequences. You had also seen Morgan cheat on exams in high school on more than one occasion. You also know that Morgan had confessed to often stealing money from his or her parents and would arrive late and leave early from a part-time job at the local McDonald's but would write in the full shift on time sheets.

You and Morgan both attended the same college nearly 500 miles away. You each majored in business, had a couple of classes together, and began sharing rides home. You got to know Morgan, and you were even glad to see a familiar face while you were so far from home. You were both accepted into the college's MBA program, and over the course of these college years, you became very good friends with Morgan; you were even in Morgan's wedding following graduation. Coincidentally, you both received attractive job offers (in separate departments) from the major employer in your hometown; you both accepted the offers and returned home.

Morgan and his or her spouse frequently socialize with you and your spouse. They often come over on weekends, and you usually meet for lunch at least once a week. Although Morgan has matured and "straightened out" for the most part, you believe that Morgan's ethical and moral standards are sometimes questionable. For example, last fall Morgan was caught being unfaithful to his or her spouse. Thankfully, they were able to repair their marriage, and this has never happened again. Morgan has also confessed to you that he or she recently lied to a supervisor to gain additional time to finish an assignment. Morgan often copies and mails personal items at the company's expense and even failed to report to payroll that a personal expenditure had not been deducted from the last paycheck. Furthermore, Morgan cheated on income iaxes a few years ago and continues to smoke marijuana on occasion. You don't mean to be keeping an ethics balance sheet on Morgan, but you have had several private discussions with Morgan regarding the questionable nature of these types of behaviors. You believe that these conversations have helped Morgan to see things in a new light and have positively impacted his or her behavior.

You've recently been promoted to District 4 manager. Your regional manager is on her way to meet with you to get your recommendation for filling the District 3 manager position. Morgan has just phoned to ask for your support and recommendation for this position. To Morgan's benciit, he or she has been a hard worker for this company, has always had positive evaluations, and is well liked. Although you feel loyalty to Morgan and know that Morgan is a good employee, you also want to make a good impression in your new position and wonder if Morgan is really the best (and safest) person to recommend for the job.

Your regional manager has just arrived at your office. She gets right to the point, asking if you have any recommendations for the District 3 manager's position. Do you recommend Morgan?

\section{Appendix $\mathrm{C}$}

\section{Discussion Questions}

- What responsibilities or obligations do the reader and Morgan owe to themselves, the organization, their profession, their peers, and the business community?

- What are the implications of their behavior and decisions?

- Does a company have the right to be interested in employees' off-work behavior? At what point does personal life spill over into work life?

- Would the type of job make a difference in your recommendation (i.e., an international assignment)?

- Should those in leadership positions be role models for subordinates?

- Should friendships in the workplace inlluence decision making? Should Morgan have asked for the recommendation?

- How is Morgan any different from you or me or the person sitting next to you? (Note to instructor: Remind students that Morgan is a compilation of all of us.) What is the implication in judging others when we may be guilty, too?

- Finally, would you or would you not recommend Morgan? Why?

- Would it make a difference if Morgan were male or female? Why?

\section{References}

Argyris, C., \& Schon, D. A. (1974). Theory in practice: Increasing professional effectiveness San Francisco: Jossey-Bass

Cavanaugh, G. F., Moberg, D. J., \& Velasquez, M. (1981). The ethics of organizational politics. Academy of Management Review, 6, 363-374

Collins, D. (1999). The dollar game: Questioning the ethics of capitalism and bargaining. Journal of Management Education, 23, 302-310.

Daft, R. L. (1991). Management (2nd ed.). Chicago: Dryden.

Daft. R. L., \& Marcic, D. (1998). Understanding management (2nd ed.). Fort Worth, TX Dryden

Dennis, L. E.. \& Stroh. L. K. (1997). A lithe jeitjnho in Brazil: A case study on intemational management. Joumal of Management Education, 21, 255-261.

Donaldson, T., \& Dunfee, T. W. (1994). Toward a unitied conception of business ethics: Integrative social contracts theory. Academy of Management Review, 19, 252-284. 
Donaldson, T., \& Werhane, P. H. (1996). Ethical issues in business: A philosophical approach (5th ed.). Englewood Cliffs, NJ: Prentice Hall.

Jones, G. J., George, J. M., \& Hill, C.W.L. (1998). Contemporary management. New York: McGraw-Hill

Kekes, J. (1988). Self-direction: The core of ethical individualism. In K. Kolenda (Ed.), Organizations and ethical individualism (pp. 1-18). New York: Pracger.

Longnecker, J. G., McKinney, J. A., \& Moore, C. W. (1988). Egoisrn and independence: Entrepreneurial ethics. Organizational Dynamics, 16, 64-72.

Mallinger, M. (1997). Decisive decision making: An exercise using ethical frameworks. Joumal of Management Education, 21, 411-417.

Robbins, S. P., \& Coulter, M. (1999). Management (6th ed.). Englewood Cliffs, NJ: Prentice Hall.

Tulega, T. (1987). Beyond the bottom line. New York: Penguin.

Wiley, C. (1995). The ABCs of business ethics: Definitions, philosophies, and implementation. Industrial Management, 37, 22-27.

\section{DEVELOPING FIRST ENCOUNTERS \\ OF THE CLOSE KIND: A BEGINNING \\ CLASS EXERCISE}

\author{
Michael R. Manning \\ New Mexico State University \\ Paula S. Weber \\ St. Cloud State University
}

Professionals are frequently required to enter into new or unknown situations: A salesperson walks into a meeting with a prospective new client, a manager represents the company at a convention luncheon, an employee faces his or her first day on a new work team, and so on. Likewise, a professor and students walk into a classroom on the first day of each new term to encounter a group of people, mostly unknown to them, with whom they will be working over the course of the semester. The salient characteristics of these situations are likely to be a lot of uncertainty, nervousness, desire for acceptance, and fear of participation. Many questions may race through one's mind: "What will these people be like? Will I enjoy this situation? Will I learn anything interesting? Will I develop friends here?" (Schein, 1988).

During a first encounter, some people plunge in and begin introducing themselves, some make jokes, some seek out others who appear to have high status, many others withdraw fearing they might be approached, and a few wait politely for someone else to initiate contact. These responses often prove to be inefficient, slow, or even counterproductive ways to build close, constructive relationships with others (Bowen, 1986). Sometimes the first impression we leave is even misleading to others who are trying to get to know us.

Authors' Note: Please address all correspondence to Michael R. Manning. College of Business Administration and Economics, New Mexico Srate University, Las Cruces, NM 881013; (phonc) 505-646-2532; (fax) 505-646-1372; (e-mail) mmanning@nmsuedu.

JOURNAL OF MANAGEMENT EDUCATION, Vol. 25 No. 5, October 2001617.623

C) 2001 Sage Publications 